\title{
A influência do curso de medicina na espiritualidade dos estudantes
}

\section{The influence of the medical course on student's spirituality}

\section{La influencia del curso de medicina en la espiritualidad de los estudiantes}

Rafahel Santos Sousa Bonfim ${ }^{1 *}$, Márcia Cristina Maciel de Aguiar. ${ }^{2}$

Como citar esse artigo. Bonfim, R. S. S; de Aguiar, M. C. M. A influência do curso de medicina na espiritualidade dos estudantes. Revista Pró-UniverSUS. 2021 Jul./Dez:; 12 (2): 78-85.

\author{
Resumo
}

Essa pesquisa objetiva analisar a influência do ensino médico na espiritualidade do estudante, buscando conhecer a espiritualidade do estudante de medicina e a sua concepção sobre este tema, e comparar a percepção do estudante de medicina sobre a importância da espiritualidade no campo da saúde, antes e depois de cursar a disciplina que aborda esta temática. Este é um estudo qualitativo baseado em narrativas orais, gravadas e, posteriormente, transcritas, seguindo o modelo de análise de dados qualitativos proposto por Graham Gibbs. Foi aplicado com os informantes um questionário sóciodemográfico e, em seguida, realizada uma entrevista estruturada. A amostra constou de estudantes de medicina, maiores de 18 anos, que estavam cursando o segundo, terceiro, quarto, sexto, sétimo ou oitavo semestre em uma universidade pública de Salvador, Ba. Os resultados mostram que o curso de medicina influenciou a maior parte dos estudantes entrevistados, e essa influência não demonstrou ser dada em função da crença, religião ou semestre em curso, mas sim de modo subjetivo de acordo a percepção pessoal que cada entrevistado possui a respeito da sua espiritualidade e das suas vivências no decorrer do curso. A grande maioria foi influenciada a favor da sua espiritualidade, acentuando e criando novas convicções, enquanto uma pequena parte relatou uma influência contrária à sua espiritualidade durante o curso, fazendo-os reconsiderar compreensões e posicionamentos anteriormente tidos. Ademais, mais da metade da amostra relatou já ter vivenciado um fato marcante na sua espiritualidade, diretamente relacionado ao curso de medicina.

Palavras-chave: Educação médica; Espiritualidade; Estudantes de Medicina.

\begin{abstract}
This research aims to analyze the influence of medical education on student spirituality, seeking to know the spirituality of medical students and their conception of this topic, and to compare the perception of the medical student on the importance of spirituality in the field of health, before and depois to attend a discipline that addresses this issue. Qualitative study based on oral narratives, recorded and, later, transcribed, following the qualitative data analysis model proposed by Graham Gibbs. I was applied as informants a sociodemographic questionnaire and, followed, conducted a structured interview. A sample consists of medical students, over 18 years of age, who were studying the second, third, fourth, sixth, seventh or eighth semester in a public university in Salvador, Ba. The results show that the medical course influenced most of the two interviewed students, and that this influence does not show to be given in the function of the birth, religion or semester in course, but in a subjective way according to the personal perception that each interviewee has in respect. Give your spirituality and your experiences do not run the course. To a great extent it was influenced in favor of his spirituality, accentuating and nurturing new nonconvictions, insofar as a small part related to a counter influence to his spirituality of the course, prompting you to reconsider previously understood understandings and positions. In addition, most of the goal of the show is related to the fact that you have experienced a marked fact in your spirituality, directly related to the medical course.
\end{abstract}

Keywords: Comprehensive Health Care; Music; Empathy; Hospital Care.

\footnotetext{
Afiliação dos autores:

${ }_{1 *}$ Acadêmico do curso de Medicina, Universidade do Estado da Bahia, Salvador, Bahia, Brasil. Email: rafahels@ hotmail.com ORCID: https://orcid.org/0000-0003-4851-365X

${ }^{2}$ Docente do curso de Medicina, doutora em Medicina e Saúde Humana, mestre em Ciências Sociais, Universidade do Estado da Bahia, Salvador, Bahia, Brasil. Email: mcrisdeaguiar@yahoo.com.br ORCID: https://orcid.org/0000-0001-7797-4530.
} 


\section{Resumen}

Esta investigación tiene como objetivo analizar la influencia de la educación médica en la espiritualidad de los estudiantes, buscando conocer la espiritualidad de los estudiantes de medicina y su concepción de este tema, y comparar la percepción del estudiante de medicina sobre la importancia de la espiritualidad en el campo de la salud, antes y luego de tomar la disciplina que aborda este tema. Estudio cualitativo basado en narrativas orales, grabadas y posteriormente transcritas, siguiendo el modelo de análisis de datos cualitativos propuesto por Graham Gibbs. Se aplicó un cuestionario sociodemográfico con los informantes y, posteriormente, se realizó una entrevista estructurada. La muestra estuvo conformada por estudiantes de medicina, mayores de 18 años, que cursaban segundo, tercero, cuarto, sexto, séptimo u octavo semestre en una universidad pública de Salvador, Bahía. Los resultados muestran que la carrera de medicina influyó en la mayoría de los estudiantes entrevistados, y esta influencia no se mostró dada de acuerdo con la creencia, religión o semestre en curso, sino subjetivamente de acuerdo con la percepción personal que cada entrevistado tiene sobre su espiritualidad y sus vivencias durante el curso. La gran mayoría fue influenciada a favor de su espiritualidad, acentuando y creando nuevas noconvicciones, mientras que una pequeña parte reportó una influencia contraria a su espiritualidad en el curso, haciéndolos reconsiderar entendimientos y posiciones asumidas anteriormente. Además, más de la mitad de la muestra refirió haber experimentado ya un hecho destacable en su espiritualidad, directamente relacionado con el curso de medicina.

Palabras clave: Educación Médica; Espiritualidad; Estudiantes de Medicina.

\section{Introdução}

O termo espiritualidade origina-se do latim spiritus ou spirituali, que significa sopro, respiração ou ar, e nele se reflete a busca de significados, de conceitos que transcendem o visível, em um sentido de conexão com algo maior que si próprio ${ }^{1}$. Espiritualidade e saúde estão emaranhadas desde a antiguidade e a importância da dimensão espiritual no exercício da medicina já é bem clara e definida ${ }^{2}$. Pacientes trazem consigo não apenas seus corpos adoecidos, mas também suas crenças, medos, convicções e, também, suas espiritualidades (ou ausência delas).

Em consonância com esta realidade, a OMS incluiu, no ano de 1998, a dimensão espiritual no conceito multidimensional de saúde ${ }^{3}$. Desde então, outras organizações e associações de relevância internacional seguiram introduzindo, paulatinamente, esse tema em suas declarações. Esta discussão também já está presente em grades curriculares em várias universidades espalhadas pelo mundo, desde a década de 90, principalmente nos Estados Unidos ${ }^{4}$. Consolidando a importância do tema espiritualidade na formação acadêmica de medicina, as Diretrizes Curriculares Nacionais mais recentes para cursos de medicina vêm apontando para a importância multidimensional da discussão deste tema no ensino médico ${ }^{5}$.

Apesar do grande número de estudos já realizados baseados no tema espiritualidade e a sua influência na saúde e, portanto, no contexto médico-paciente, terapêutica e prognóstico ${ }^{6}$, são escassas as pesquisas, até o momento da realização deste estudo, que objetivaram responder se o ensino médico, ao privilegiar a abordagem baseada em evidências, na medida em que supervaloriza a construção de um modelo de saúde biomecânico e cientificista $^{7}$, influencia, mesmo que insidiosamente, na espiritualidade ou na percepção sobre espiritualidade do estudante de medicina, futuro profissional que lidará com essas questões no exercício de sua profissão, o que torna esse o objetivo principal deste estudo. Ademais, a caracterização da espiritualidade do estudante e a compreensão sobre esta temática também foram tópicos abordados nesta pesquisa.

\section{Metodologia}

Trata-se de um estudo de abordagem qualitativa, a partir de narrativas orais, sendo a Universidade do Estado da Bahia (UNEB) o campo empírico, localizado em Salvador, Bahia. De acordo com a Resolução 466/12 do Conselho Nacional de Saúde, a pesquisa foi aprovada pelo Comitê de Ética em Pesquisa (CEP) da UNEB sob o número da CAAE 12352919.6.0000.0057.

A população alvo foi estudantes de medicina da faculdade, convidados randomicamente pelopesquisador a participar da entrevista de forma voluntária. Como o curso de Medicina da Universidade campo deste estudo possui em sua grade curricular de disciplinas obrigatórias o componente Psicologia Médica e Espiritualidade, no quinto semestre, a amostra foi dividida em duas partes, sendo a primeira composta por estudantes do segundo ao quarto semestre, e a segunda do sexto ao oitavo semestre. Antes das entrevistas, cada participante concordou e assinou o Termo de Consentimento Livre e Esclarecido (TCLE). Os dados foram coletados de agosto de 2019 a março de 2020.

Os critérios de inclusão foram: ser maior de 18 anos, estar matriculado no curso de medicina da UNEB, e estar cursando o segundo, terceiro, quarto, sexto, sétimo ou oitavo semestre. Critérios de exclusão: aqueles que não aceitaram assinar o TCLE, que se opuseram, ao longo da entrevista, a responder alguma das questões feitas pelo pesquisador ou que recusaram a ter suas respostas gravadas durante o processo de coleta de dados. Para a coleta dos dados foi aplicado um questionário sociodemográfico com questões de interesse deste estudo e gravada uma entrevista estruturada que 
seguiu ao roteiro previamente elaborado. Para garantir o anonimato no estudo, foram escritas apenas as iniciais dos nomes dos participantes no questionário e criados pseudônimos na apresentação dos resultados.

De posse das informações, foi utilizado o método de Análise de Conteúdo ${ }^{8}$. No primeiro contato com os dados, foi realizada a transcrição do material gravado em formato audiodigital. De posse dos transcritos, foi feita uma leitura do material e, posteriormente, a criação de núcleos de sentido, sendo agrupados em categorias e subcategorias, seguindo o modelo de análise de dados qualitativos de $\mathrm{Gibbs}^{9}$, complementado por uma estatística descritiva por frequências com o intuito de corroborar com a compreensão da análise qualitativa das respostas, também, por meio da quantificação das categorias e subcategorias. Por último, foi feito um diálogo entre os núcleos de sentido e informações provenientes de outros estudos acerca do assunto, na busca da fundamentação na literatura referente ao tema, seguido de uma análise imparcial dos dados e conclusão pertinentes aos resultados encontrados 8 .

\section{Resultados e Discussão}

Foram entrevistados um total de 24 (vinte e quatro) estudantes de medicina, divididos igualmente entre os seis semestres definidos previamente pela metodologia deste estudo. Quanto à crença em uma divindade ou força superior metafísica, 87,5\% possuíam crença em alguma deidade e 12,5\% declararam-se ateus. $75 \%$ afirmaram possuir uma religião, sendo a maioria católica, seguida de protestantes, espíritas e adventistas do sétimo dia. Dentre os religiosos, 83,3\% afirmaram ser praticantes de suas religiões, sendo todos os não praticantes de religião católica.

\section{Eixo da Narrativa: Conceito de Espiritualidade}

A partir deste tópico, foram identificadas cinco principais categorias que exprimem o conceito de espiritualidade dado pelos estudantes de medicina: algo não explicável (41,7\%); relação com ser superior ou deidade $(29,1 \%)$; força para lidar com desafios da vida $(16,7 \%)$; forma de conexão consigo mesmo e com o mundo ( $8,3 \%)$; e forma de encarar questões ontológicas que abordam o sentido e a totalidade da vida $(4,2 \%)$.

O padrão de conceitos mostrou-se heterogêneo, inclusivenosestudantesquejátinhamcursadoadisciplina Psicologia Médica e Espiritualidade, o que parece apontar para a dominância de uma conceitualização subjetiva, mais influenciada por vivência pessoal, do que acadêmica.

\section{Eixo da Narrativa: Presença de uma Espiritualidade}

Se consideraram possuidores de uma espiritualidade 95,8\%, independentemente de religião. Ao cruzar os dados das respostas orais com dados do questionário escrito, foi observado que $65,2 \%$ dos possuidores de uma espiritualidade criam em alguma divindade, eram religiosos e praticavam sua religião. 13\% acreditavam em uma divindade e eram religiosos não praticantes. Outra parcela igual também cria na existência de uma divindade, porém não possuía nenhuma religião. E 8,6\% afirmaram possuir uma espiritualidade, embora fossem ateus.

A presença de uma espiritualidade não dependeu, necessariamente, da presença de uma vida religiosa em atividade, nem da crença em um Deus. De religiosos praticantes a ateus, observou-se a existência de uma espiritualidade no cotidiano ou na forma de ver o mundo em volta, seja ela construída sobre um arcabouço dogmático religioso ou fundamentada em interpretações subjetivas com limites imprecisos. De acordo com Bernardino $^{10}$, a espiritualidade é uma dimensão constitutiva humana, estando sempre presente no cotidiano, entre agnósticos e ateus, em todos os tempos e momentos da nossa existência.

A existência de alunos que possuem uma espiritualidade, embora não professem alguma religião, também foi encontrada, de forma semelhante, em outros estudos com acadêmicos de medicina ${ }^{11 ; 12}$. Estes dados também concordam com o censo do IBGE de $2010^{13}$ e demonstram que a população brasileira, mesmo de jovens, manifesta sua transcendente espiritualidade independentemente da religiosidade ou da herança religiosa familiar.

\section{Eixo da Narrativa: Prática de Atividades Espirituais/Religiosas}

Sobre a realização de práticas relativas à espiritualidade ou religião, 83,3\% afirmaram realizá-las no seu cotidiano. Destacaram-se: rezar/orar, frequentar cultos/missas ou reuniões, e ler livros sagrados ou de conteúdos relativos à sua religião (todos do subgrupo de religiosos praticantes); hábitos derivados de uma religião herdada, como se benzer todos os dias e orar antes de dormir $(66,7 \%$ dos religiosos não praticantes); contemplação da natureza, rituais subjetivos de aproximação com o sagrado e leitura sobre espiritualidade e vertentes filosóficas que tratam desta temática $(66,7 \%$ dos que apenas criam em Deus, sem professarem uma religião); e práticas subjetivas, como busca de equilíbrio emocional e autorreflexão sobre a vida (33,3\% dos ateus). 
De acordo com Silva ${ }^{14}$, as práticas da espiritualidade podem ser agrupadas em ações intrinsicamente religiosas e/ou atividades não diretamente ligadas à religião, como aquelas herdadas familiarmente. Não obstante práticas espirituais também podem estar esteticamente desvinculadas de religião. Em geral, essas ações são mais subjetivas, intrínsecas nas relações diárias e, muitas vezes, imperceptíveis socialmente como práticas de espiritualidade ${ }^{15}$.

\section{Eixo da Narrativa: Influência do Curso na Espiritualidade}

$79,2 \%$ dos entrevistados tiveram a percepção de que, sim, houve uma influência por parte do curso, enquanto $20,8 \%$ responderam que não houve nenhuma influência da graduação em sua espiritualidade, até a entrevista.

Não houve padrão de influência do curso na espiritualidade do estudante de acordo a sua crença, religião ou semestre cursado, de modo que a existência de uma influência se deu de modo subjetivo de acordo a percepção pessoal que cada entrevistado possui a respeito da sua espiritualidade e das suas vivências no decorrer do curso.

Dentro do grupo que se sentiu influenciado, foram delimitadas as categorias: influência a favor da espiritualidade do participante $(84,2 \%)$; e influência contrária à espiritualidade $(15,8 \%)$.

\section{A favor da espiritualidade}

Como principais influências positivas sobre a espiritualidade, acentuando convicções dentro da percepção sobre espiritualidade que cada um possui, destacaram-se as seguintes subcategorias:

- Ausência de respostas (42,2\%)

A falta de respostas e explicações da medicina ocidental diante de questionamentos diversos foi dada como principal fator influenciador da espiritualidade, reforçando a crença na existência de um ser superior nestes estudantes e aproximando-os de convicções metafísicas. As justificativas perpassam por: limitação científica em provar teorias propostas; inexatidão da ciência a respeito do comportamento do organismo humano, como recuperações inexplicáveis de pacientes graves; falhas terapêuticas e erros médicos.

"Eu acredito que muita coisa que vivenciamos, na prática médica, Deus está colocando a sua mão. Há muitas doenças que trazem risco à vida e o paciente consegue sair de uma forma milagrosa. Eu creio que há algo sobrenatural". (Elias - terceiro semestre)
De acordo com Anderson e Rodrigues ${ }^{16}$, na metodologia investigativa presente no campo de saúde, o paradigma anatomoclínico, que constituiu as bases da medicina cientifica, é de cunho cartesiano. Embora esse paradigma tenha gerado muitos benefícios à prática médica, dá mostras de sua insuficiência e inadequação para abordar plenamente os fenômenos relacionados ao processo saúde-adoecimento, o padrão de morbimortalidade, o comportamento do organismo humano e a expectativa de vida na atualidade ${ }^{16}$. Portanto pode-se concluir que o paradigma médico-científico gera lacunas no conhecimento na medida em que ele não dispõe de todas respostas frente a todas as perguntas científicas. Neste contexto, o fenômeno espiritual/ religioso emerge como um viés para preencher este espaço vazio na busca pelo conhecimento humano ao cumprir um papel de facilitador sobre a compreensão do inexplicável e a aceitação do que nunca fora imaginado ${ }^{17}$.

\section{- Complexidade do organismo humano $(26,3 \%)$}

Ao estudar matérias, como a bioquímica dos processos intracelulares, biologia celular, anatomia humana e fisiopatologia. Vários estudantes mencionaram a complexidade e perfeição do corpo humano como principal influência favorável do curso sobre a espiritualidade, o que só pode ser justificada pela criação sobrenatural por uma divindade.

\footnotetext{
"Quando eu estudo uma célula, vejo que existe uma maquinaria muito grande ali e uma engenharia. Tudo que se observa na natureza, tal como o corpo humano, requer uma inteligência por trás. Um projetista que pensa [...]". (Isaque - oitavo semestre)
}

É possível afirmar, na atualidade, que a biologia tal como incorporada à medicina anatomoclínica, é uma biologia limitada e insuficiente para explicar os fenômenos orgânicos em sua complexidade, embora ainda predomine no campo do ensino promovido por considerável número de escolas médicas ${ }^{18}$. No campo das ciências físicas e biológicas, figuras como Einstein (1934) e, mais recentemente, Francis Collins, diretor do Projeto Genoma, em 2001, são notórios expoentes da defesa da espiritualidade na estrutura do ser humano ${ }^{19}$.

\section{- Resiliência do paciente $(15,8 \%)$}

Alguns entrevistados, relataram experiências com o comportamento de pacientes frente ao processo de adoecimento como principal instrumento de estímulo às suas espiritualidades proporcionado pelo curso.

"[...] muitos pacientes acreditam que com a fé vão superar aquilo. $O$ contato com o paciente me faz ter uma visão mais espiritual". (Eva - sétimo semestre) 
Algumas das possíveis explicações de como a espiritualidade pode afetar a saúde são o respeito ao corpo, gerando melhor nutrição e melhores hábitos de vida; melhor estado psicológico por incentivar perdão, esperança, altruísmo e amor; e redução do estresse $^{20}$. A espiritualidade e o envolvimento em religiões podem proporcionar aumento do senso de propósito e significado da vida, que são associados à maior resiliência e resistência ao estresse relacionado às doenças $^{21}$.

\section{Contrária à espiritualidade}

Alguns estudantes entenderam que o curso aborda temáticas que são antagônicas às suas espiritualidades, desestimulando-a de forma generalizada, em função de todo o seu arcabouço cientificista e racional, ou de forma pontual em temáticas específicas, como no caso de psiquiatria, fazendo-os reconsiderar algumas convicções existentes antes de cursarem medicina.

"A medicina me deixa mais cético. Algumas coincidências relacionadas ao corpo[...] eu penso: 'ah, mas isso ainda não tem explicação"’." (Davi - quarto semestre)

"Algumas condições psiquiátricas [...] eu achava que tinha algum componente espiritual envolvido no estado íntimo da pessoa. Depois que eu entrei no curso, entendi o que é o adoecimento psíquico e dissociei uma coisa da outra. Hoje eu penso de forma mais cientifica". (Esdras - sexto semestre)

Nota-se um fator intrínseco na visão científica de Davi: o naturalismo. A visão de mundo que prevalece nas disciplinas de saúde tem raízes no empirismo e nas ciências naturais, que tem como base metodológica, o naturalismo (a visão de que todos os fenômenos podem ser explicados, metodológica e racionalmente, com base nas leis e nas causas naturais) ${ }^{22}$.

É válido ressaltar que a ótica naturalista na ciência nem confirma, nem nega questões metafísicas, tais como a espiritualidade, porém as metodologias científicas legitimamente fundamentadas no naturalismo metodológico, ao darem ênfase nessa cética visão empírica-racional, deixam em segundo plano outras epistemologias as quais podem servir de um legítimo ponto de partida para o estudo das realidades espirituais ${ }^{22}$. A racionalização pode, desse modo, corroborar com a obstrução do fluxo da experiência afetiva espiritual, podendo ser, inclusive, um mecanismo de defesa que leva o sujeito a um comportamento de justificar e explicar, de forma superficial, a própria experiência ${ }^{23}$.

A relação entre adoecimento mental e cultura/ experiência religiosa, vivenciada por Esdras e também presente em outras respostas, é muito discutida dentro do campo de saúde. Essa relação foi trabalhada por Carl
Gustav Jung ao estabelecer a compreensão e a diferença entre saúde mental e vivências puramente espirituais. Segundo ele, as vivências espirituais não podem ser confundidas com os quadros da psicopatologia e, por outro lado, as afecções psicopatológicas não podem ser consideradas componentes/vivências espirituais ${ }^{24}$.

\section{Eixo da Narrativa: Fato marcante na Espiritualidade}

Sobre a ocorrência de algum fato marcante no âmbito da espiritualidade, durante o curso, 54,2\% afirmaram já ter vivenciado algum episódio que levou a uma reflexão sobre o tema, enquanto $45,8 \%$ relataram não ter vivenciado nenhum fato até o momento da entrevista.

Observou-se que a percepção da vivência de um fato que marcou a espiritualidade não dependeu da crença/religião do estudante, nem da existência de uma influência do curso em sua espiritualidade até o presente momento. Entretanto, dentre os que afirmaram ter vivenciado um fato marcante, a maioria $(92,3 \%)$ também se considerou influenciada pelo curso de alguma forma.

Dentre o grupo que vivenciou um episódio notável, foram mencionadas, principalmente, experiências relacionadas a pacientes em contexto de atendimento, nas aulas práticas, em unidades de saúde; além de experiências voltadas ao próprio ensino médico.

\section{Experiências relacionadas a pacientes}

Dentre os fatos marcantes na sua espiritualidade relacionados a pacientes, foram encontradas as seguintes subcategorias:

- Testemunho de fé (40\%)

A maior parte dos estudantes que vivenciou algum episódio relacionado a pacientes relatou $\mathrm{o}$ comportamento de fé e esperança destes, diante do processo de adoecimento, como principal fato marcante na sua espiritualidade. $\mathrm{O}$ exercício da fé, mediante uma situação de adversidade, é um tema muito cogitado por profissionais e alvo de intensas pesquisas executadas por cientistas de todo o mundo ${ }^{25}$.

A Bíblia Sagrada, literatura mais vendida de todos os tempos ${ }^{25}$, versa sobre o assunto. No livro de Hebreus, por exemplo, todo o capítulo 11 fala sobre a fé, a começar pelo versículo 1: "A fé é a certeza de que vamos receber as coisas que esperamos e a prova de que existem coisas que não podemos ver" ${ }^{26}$. Levando em consideração que, por séculos, o mundo ocidental foi vastamente influenciado pela cultura judaico-cristã, e que a maior parte dos entrevistados deste estudo 
consideram-se cristãos $(77,7 \%$, somando cristãos católicos e protestantes), entender o conceito de fé sob esta ótica torna-se relevante para agregar a discussão sobre o tema.

Independentemente de vinculado ou não à religião, da ação biológica que a fé tem sobre o organismo humano e do desfecho clínico que o paciente possa ter, torna-se claro que o comportamento de fé em pacientes com situação grave de saúde é comum de ser observado e este pode influenciar a percepção sobre espiritualidade daqueles que possuem contato direto com este fenômeno.

- Reflexão sobre brevidade da vida e a morte (30\%)

Alguns estudantes relataram reflexões que tiveram diante da morte e de pacientes graves sobre a brevidade/fragilidade da vida, medo e insegurança. Essas reflexões marcaram as suas espiritualidades e ficaram registradas em suas memórias. A experiência de sofrimento conecta-se à espiritualidade quando o indivíduo, ao buscar extrair um significado diante da adversidade, busca refletir a respeito de sua limitada e frágil condição humana e age no sentido de transcendê$1 a^{27}$.

- Relação de afeto com o paciente (20\%

Outros estudantes relataram sobre a relação médico-paciente construída ao longo de uma anamnese e o impacto que isso causou na vida deles. $\mathrm{O}$ afeto, a empatia, a identificação pessoal e a rica troca de experiências e aprendizado foram fatores levantados como positivos para as suas espiritualidades.

A afetividade existe inevitavelmente, na medida em que ela se refere a um contato entre pessoas. Desta forma, por mais que se procure manter um distanciamento, sentimentos estarão sempre presentes, nas mais variadas formas, como afeição, empatia, antipatia, compaixão, etc ${ }^{28}$. O próprio termo "relação médico-paciente" conota parceria, troca de saberes, construção e empatia; especialmente a empatia com tratamento respeitoso, a escuta atenta sem julgamentos e a troca de experiências são características esperadas desta relação, e estes fatores geram vínculo entre o profissional e o paciente ${ }^{29}$.

- Recuperação de paciente em condição grave (10\%)

Dentre os estudantes, também foi relatado o fato de presenciar a recuperação improvável de um paciente grave como fator positivo para a espiritualidade, reforçando a crença da existência algo sobrenatural nesse contexto; e o curso de medicina propiciou esta experiência.

A ausência de respostas, como fator influenciador positivo da espiritualidade dos estudantes, já abordado neste estudo, intersecciona com este tópico, visto que a reflexão sobre orestabelecimento de saúde deumpaciente grave torna-se um fato marcante na espiritualidade do estudante, observado quando a medicina não consegue explica-lo totalmente e o prognóstico desse paciente muda drasticamente. Há na literatura crescentes evidências de que a espiritualidade implica fator de proteção, tanto em questões físicas de ordem médica, quanto em problemas da área psicológica ${ }^{30}$.

\section{Experiências relacionadas ao ensino médico}

Uma pequena parte dos entrevistados relatou, como fato marcante para a sua espiritualidade, a percepção do sagrado em exame físico durante aulas práticas e discussões pontuais com professores e monitores sobre a importância da fé no contexto de saúde e a existência de um ser superior.

O contato com os professores e a vivência clínica moldam as atitudes dos estudantes em relação aos colegas e aos próprios pacientes. O modo como a espiritualidade é ensinada pelos docentes e percebida pelos alunos pode levar a uma compreensão mais profunda dessa dimensão, na própria assistência ao paciente $^{31}$, e também a uma reflexão e influência sobre a sua própria espiritualidade.

\section{Eixo da Narrativa: Importância da Espiritualidade no Campo de Saúde}

Todos os estudantes entrevistados concordaram sobre a importância desta temática na área de saúde. Essa visão não possuiu relação com as características pessoais dos participantes, nem com as suas convicções prévias sobre a temática abordada, mas parece estar relacionada com um consenso geral compartilhado na sociedade de que o exercício da espiritualidade pode trazer benefícios a diversos atores no campo de saúde. Não houve mudança no padrão de respostas entre os estudantes que cursaram a disciplina Psicologia Médica e Espiritualidade.

Uma menor parte dos entrevistados abordou, também, o lado negativo que o exercício desmedido de uma espiritualidade pode trazer no campo de saúde, na perspectiva do paciente adoecido.

\section{Benefícios da espiritualidade}

Ao abordar os benefícios do exercício de uma espiritualidade, foram mencionadas vantagens aos diferentes atores existentes no contexto de cuidado em saúde e ensino médico, a saber: 
- Profissionais de saúde (75\%)

A maioria dos estudantes entende que o exercício da temática nos atendimentos auxilia o profissional a ser mais humano, empático, sensibilidade e percepção em relação aos seus pacientes. Outros mencionaram benefícios para o próprio profissional ao amplificar as suas experiências dentro da profissão, ressignificando as experiências intrínsecas à atuação médica e dandolhe bem-estar e equilíbrio emocional ao ajudar a lidar com as dificuldades encontradas no exercício médico.

\section{- Pacientes diante do sofrimento $(62,5 \%)$}

Ao estabelecer relações entre a espiritualidade e pacientes, muitos estudantes correlacionaram o exercício de uma espiritualidade como benefício diante do adoecimento e sofrimento. Ser espiritual, nesses momentos, pode representar um maior suporte psicológico, força e esperança para superação de um momento ruim.

\section{- Estudantes de saúde (20,5\%)}

Para o benefício pessoal, alguns estudantes afirmaram que ser espiritual durante o curso propicia um suporte emocional maior para enfrentar as dificuldades inerentes ao curso, como a extensa carga horária e os muitos compromissos acadêmicos. Já outros entrevistados observaram que a espiritualidade é necessária para o estudante como tema a ser estudado, visto que o domínio desta área será de uso importante como ferramenta na profissão.

\section{Malefícios da espiritualidade}

Uma pequena parte dos estudantes abordou, além dos benefícios, o lado negativo que o exercício de uma espiritualidade pode trazer no campo de saúde, seja pelo próprio paciente ou por terceiros em sua volta, caso não seja utilizada de forma equilibrada. As críticas levantadas abordaram questões relacionadas ao mau uso da espiritualidade, dentro de um contexto religioso, quando esta estigmatiza o adoecimento e espiritualiza condições médicas, interferindo, em alguma medida, no enfrentamento da doença e no seguimento do tratamento médico estabelecido. A área da medicina mais exemplificada foi a psiquiatria.

\section{Conclusão}

Estudar o tema espiritualidade sob o olhar do discente, analisar o comportamento da sua espiritualidade ao longo da graduação e iniciar uma discussão sobre a influência do curso sobre ela foram objetivos deste estudo. Além disso, ao juntar-se a outras pesquisas afim de agregar a discussão sobre a relevância deste tema durante a formação médica, esse estudo foi essencial para ratificar a importância do tema espiritualidade na graduação de medicina e a sua relevância na área da saúde. Apesar de ainda carecer de uma maior discussão nas escolas médicas brasileiras, essa temática é motivo de crescente interesse nas pesquisas por todo o mundo, dada a sua importância.

$\mathrm{O}$ curso de medicina influenciou a maior parte dos estudantes entrevistados, e essa influência não demonstrou ser dada em função da crença, religião ou semestre em curso, mas sim de modo subjetivo de acordo a percepção pessoal que cada entrevistado possui a respeito da sua espiritualidade e das suas vivências no decorrer do curso. A grande maioria foi influenciada a favor da sua espiritualidade, acentuando convicções dentro da percepção sobre espiritualidade que cada um já possuía, enquanto uma pequena parte relatou uma influência contrária à sua espiritualidade do curso, em oposição a crenças antes tidas, fazendo-os reconsiderar algumas convicções, sendo que mais da metade da amostra relatou já tinha vivenciado um fato marcante na sua espiritualidade, diretamente relacionado ao curso de medicina.

Esse estudo apresenta limitações de uma pesquisa qualitativa, contextualizada no local e tempo da investigação, e do universo dos participantes. Os resultados não propõem generalizações, no entanto, podem contribuir para ampliar o conhecimento e a reflexão sobre o tema, como também servir de exemplo para novas pesquisas semelhantes em outras áreas de saúde, como psicologia e enfermagem, a fim de enriquecer o conhecimento sobre o comportamento da espiritualidade em outros contextos e sobre a abordagem espiritual em suas áreas de atuação.

\section{Referências}

1. Guimarães HP, Avezum A. O impacto da espiritualidade na saúde física. Revista de Psiquiatria Clínica. 2007; 34 (1): 88-94.

2. Ghadirian AM. Is spirituality relevant to the practice of medicine? Med Law. 2008; 27 (2): 229-39.

3. World Health Organization. Division of mental health and prevention of substance abuse. WHOQOL and spirituality, religiousness and personal beliefs (SRPB). Genève: 1998 (Report on WHO consultation)

4. Dal-Farra RA, Geremia C. Educação em Saúde e Espiritualidade: Proposições Metodológicas. Revista Brasileira de Educação Médica. 2010 34 (4): 587-97.

5. Nery RM, Pietrobon RC, Machado CLB, Come JC, Manfroi WC. Espiritualidade No Ensino Médico. Saúde Integrada. 2014; 7 (13-14): 209 17.

6. Stefanek M, McDonald PG, Hess SA. Religion, spirituality and cancer: current status and methodological challenges. Psychooncology. 2005;14 (6): 450-63. 
7. Swick HM. Toward a normative definition of medical professionalism. Acad Med. 2000 Jun.; 75 (6): 612-6.

8. Moraes R. Análise de conteúdo. Revista Educação. 1999; 22 (37): 7-32.

Gibbs G. Análise de dados qualitativos. Porto Alegre: Artmed; 2009.

10. Silva JB, Silva LB. Relação entre religião, espiritualidade e sentido da vida. Revista da Associação Brasileira de Logoterapia e Análise Existencial. 2014; 3 (2): 203-15.

11. Zanetti GC, Lemos GL, Gotti ES, Tomé JM, Silva AP, Rezende EAMR. Percepção de Acadêmicos de Medicina e de Outras Áreas da Saúde e Humanas (Ligadas à Saúde) sobre as Relações entre Espiritualidade, Religiosidade e Saúde. Revista Brasileira de Educação Médica. 2018; 42 (1): 67-74.

12. Lucchetti G, Oliveira LR, Koenig HG, Leite JR, Lucchetti AL; SBRAME Collaborators. Medical students, spirituality and religiosity results from the multicenter study SBRAME. BMC Med Educ. 2013 Dez.; 13 (1): 162 .

13. Instituto Brasileiro de Geografia e Estatística - IBGE. Censo Demográfico 2010. Características gerais da população, religião e pessoas com deficiência. Rio de Janeiro, 2010; p.89-105. [acesso em 18 junho 2020]. Disponível em: http://biblioteca.ibge.gov.br/visualizacao/periodicos/94/ cd_2010_religiao_deficiencia.pdf

14. Silva DIS. Significados e práticas da espiritualidade no contexto dos cuidados paliativos em pacientes oncológicos adultos. Revista HCPA. 2011; 31 (3): 353-8.

15. Barbosa RMM, Ferreira JLP, Melo MCB, Costa JM. A Espiritualidade como estratégia de enfrentamento para familiares de pacientes adultos em Cuidados Paliativos. Revista SBPH. 2017 jan./jun.; 20 (1): 165-82.

16. Anderson MI P, Rodrigues RD. O paradigma da complexidade e os conceitos da medicina integral: saúde, adoecimento e integralidade. Revista HUPE. 2016; 15 (3): 242-52.

17. Rocha PT, Lima CA, Dias OV, Paiva PA, Rocha JFD. A Influência da Espiritualidade e da Religiosidade no Tratamento Oncológico: percepção da pessoa com câncer. Rev. Tendên. da Enferm. Profis. 2016; 8 (4): 2031-6.

18. Arias P, Arzt E, Bonet J, et al. Estrés Y Procesos de Enfermedad: Psiconeuroimunoendocrinologia. Modelos de integración mente-corpo. Argentina: Biblos; 1998.

19. Monteiro DMR. Espiritualidade e saúde na sociedade do espetáculo. O Mundo da Saúde. 2007 abr./jun.; 31 (2): 202-13.

20. Saad M, de Medeiros R. Espiritualidade e saúde. Einstein: Educ Contin Saúde. 2008; 6 (3): 135-6.

21. Lawer KA, Younger JW. Theobiology: an analysis of spirituality, cardiovascular responses, stress, mood, and physical health. J. Relig. Health. 2002; 41 (4): 347-62.

22. Benko MA, da Silva MJP. Pensando a espiritualidade no ensino de graduação. Rev. Latino-Am. Enfermagem. 1996; 4 (1):71-85.

23. Oliveira MR, Junges JR. Saúde mental e espiritualidade/religiosidade: a visão de psicólogos. Estudos de Psicologia. 2012 set./dez.; 17 (3): 469-76.

24. Jung CG. Psicologia da religião ocidental e oriental. Petrópolis: Vozes; 1980.

25. Costa JWN, Zarpelan LDO, da Silva JJ. A fé como propulsora para enfrentar doenças do novo século. Colloquium Humanarum. 2015; 12 (1): $10-6$.

26. Hebreus. In A Bíblia: Nova Tradução na Linguagem de Hoje. Rio de Janeiro: King's Cross Publicações; 2007.

27. Angelo M. Ouvindo a voz da família: narrativas sobre sofrimento e espiritualidade. O Mundo da Saúde. 2010; 34 (4): 437-43.

28. Fernandes JCL. A quem interessa a relação médico paciente? Cadernos de Saúde Pública. 1993 jan./mar.; 9 (1): 21-7.

29. Stock FS, Sisson MC, Grosseman S. Percepção de estudantes de medicina sobre aprendizagem da relação médico-paciente após mudança curricular. Rev. bras. educ. med. 2012; 36 (1): 5-13.

30. Volcan SMA, Sousa PLR, Mari JDJ, Horta BL. Relação entre bemestar espiritual e transtornos psiquiátricos menores: estudo transversal. Revista de Saúde Pública: 2003; 37 (4): 440-5.

31. Ermel RC, Vieira M, Tavares TF, Furuta PM, Zutin TL, Caramelo AC. O bem-estar espiritual dos professores de medicina e de enfermagem. Rev enferm UFPE online. 2015; 9 (1): 158-63. 
DO110.21727/ 